\title{
Magnetic Resonance Imaging of Central Nervous System Lesions in HIV/AIDS: About 35 Cases in Libreville (Gabon)
}

\section{Sessi Miralda Kiki'1,2, Kofi Mensa Savi de Tové2 ${ }^{2}$ Sonia Adjadohoun³, Gaelle Ebinda Mipinda1, Djivèdé Akanni' ${ }^{2}$, Patricia Yèkpè-Ahouansou ${ }^{3}$, Olivier Biaou ${ }^{3}$, Lucien Mwanyombet ${ }^{1}$, Philomène Kouna Ndouongo ${ }^{1}$}

${ }^{1}$ Radiology Department of the El RAPHA Polyclinic in Libreville, Libreville, Republic of Gabon

${ }^{2}$ Regional and Teaching Hospital of Borgou/Medical Imaging Department, Faculty of Medicine, University of Parakou, Parakou, Republic of Benin

${ }^{3}$ Medical Imaging Department, Faculty of Health Sciences, University of Abomey Calavi, Cotonou, Republic of Benin Email: gracekik@yahoo.fr

How to cite this paper: Kiki, S.M., de Tové, K.M.S., Adjadohoun, S., Mipinda, G.E., Akanni, D., Yèkpè-Ahouansou, P., Biaou, O., Mwanyombet, L. and Ndouongo, P.K. (2020) Magnetic Resonance Imaging of Central Nervous System Lesions in HIV/AIDS: About 35 Cases in Libreville (Gabon). Open Journal of Radiology, 10, 203-214.

https://doi.org/10.4236/ojrad.2020.104020

Received: October 9, 2020

Accepted: December 1, 2020

Published: December 4, 2020

Copyright (c) 2020 by author(s) and Scientific Research Publishing Inc. This work is licensed under the Creative Commons Attribution International License (CC BY 4.0).

http://creativecommons.org/licenses/by/4.0/

\begin{abstract}
Background: Sub-Saharan Africa is the region most affected by the Human Immunodeficiency Virus (HIV) with an increasing prevalence of related cognitive impairments. Magnetic Resonance Imaging (MRI) plays an important role in the early detection of lesions. This work aimed to describe the MRI aspects of different brain lesions occurred in HIV positive patients in our practice. Methods: This was a descriptive cross-sectional study that took place from June 2014 to July 2016 in the medical imaging department of the EL RAPHA private Polyclinic in Libreville, Gabon. It included all patients referred for imaging for the exploration of a Central Nervous System (CNS) lesions at MRI, based on clinical and/or paraclinical arguments. Results: Among the 39 patients included, $19(48.7 \%)$ had a previous brain CT scan, 11 of which were normal (28.2\%). Thirty-five (89.74\%) patients had a pathological MRI. The main etiologies found were toxoplasmosis (37.14\%), tuberculosis (17.14\%), cerebral atrophy (17.14\%) and HIV encephalitis (14.28\%). Among the eleven patients with a normal Computer Tomography scan, the MRI found 7 abnormalities including 1 case of toxoplasmosis, 3 cases of HIV encephalitis and 3 cases of Progressive Multifocal Leukoencephalopathy (PML). Conclusion: MRI played an important role in the diagnosis of CNS disorders in HIV-infected individuals. It can be used to differentiate and characterize various brain lesions. Improving its accessibility in sub-Saharan Africa should contribute to better care for people living with HIV.
\end{abstract}




\section{Keywords}

HIV Infection, Central Nervous System, Toxoplasmosis, Tuberculosis, Magnetic Resonance Imaging

\section{Introduction}

Sub-Saharan Africa is the region most affected by the Human Immunodeficiency Virus (HIV) with about 25.5 million cases, or $70 \%$ of the global burden of this disease [1]. Statistics also vary between countries in this part of the continent. In the case of Gabon, in 2012, the Demographic and Health Survey found a prevalence of $4.1 \%$. This was twice as high among women, with a rate of $5.8 \%$ compared to $2.2 \%$ among men [1].

The high vulnerability of organism with multi-visceral damages during this state of untreated immunosuppression by antiretroviral (ARV) drugs is no longer to be demonstrated. Among these, morbid manifestations of the Central Nervous System (CNS) can occur at all stages of HIV infection, particularly in the AIDS disease stage. Their prevalence varies from $40 \%$ to $70 \%$ according to clinical studies and even reaches $100 \%$ in some autopsy series [2].

In Africa, HIV-associated neurological damages vary between $34.0 \%$ and $42.5 \%$ in Nigeria, and up to $75 \%$ in South Africa [3] [4]. They currently affect more than 11 million Africans and thus constitute a diagnostic and therapeutic emergency [4]. The occurrence of neurological clinical manifestations requires an emergency brain scan [5], which is not always possible in our working conditions for many reasons such as the precariousness of patients and the accessibility of advanced diagnostic tools; so much that some of these conditions are over-treated without diagnostic proof.

Magnetic Resonance Imaging (MRI) is much more sensitive than Computer Tomography (CT) for the detection of early and/or small lesions, as well as lesions poorly visualised by CT [6]. Unfortunately, MRI is still not widely available and accessible in most sub-Saharan African countries.

The aim of this work was to show the contribution of MRI in the diagnosis of brain lesions encountered in HIV positive patients in our practice.

\section{Method}

\subsection{Type and Period of Study}

This was a cross-sectional descriptive study, with data collection over a 24-month period from July 2014 to July 2016.

\subsection{Study Site}

The study took place in the medical imaging department of the EL RAPHA private Polyclinic in Libreville, Gabon. 


\subsection{Patients}

We carried out an exhaustive sampling by systematic census of all HIV-positive patients referred for MRI on suspicion of CNS involvement on the basis of clinical (infectious syndrome, confusional or cerebellar syndrome, or deficiency) and/or biological arguments, and who may or may not have had a previous brain scan.

\subsection{Data Collection}

After collecting epidemiological and clinical information's, an MRI examination was carried out with a high field machine (1.5 Tesla). The protocol included morphological sequences (FLAIR, $\mathrm{T} 1, \mathrm{~T} 2, \mathrm{~T} 2^{\star}$ ), diffusion sequences, as well as a 3D T1 Vibe sequence after injection of $10 \mathrm{ml}$ of gadolinium. Two Radiologists carried out the interpretation of the images. In case of discrepancies, the opinion of a third radiologist was required.

All the data was recorded on a survey form filled in by us.

\subsection{Main Variables}

The parameters studied were demographic data (age, sex), clinical signs of orientation, lesions observed on brain CT scan (if applicable), those found on MRI and the diagnoses retained.

\subsection{Diagnostic Criteria}

The diagnosis was retained globally on the basis of a cluster of clinical, biological and radiological arguments:

- Cerebral Toxoplasmosis: Evocative aspect (annular elevation within an important edema, topography) in imaging associated with Toxoplasma gondii positive serology in serum IgG and regression of radiological signs under specific treatment.

- Tuberculosis: Typical appearance in "grape clusters" in imaging. Active lesions or squeal of pulmonary tuberculosis if present have guided the diagnosis. Concerning, clinical improvement under specific treatment of tubercular abscesses and meningitis was of great help in confirming the diagnosis.

- Cortical atrophy: Dilatation of the cortical grooves with absence of parenchymal or meningeal lesions associated in imaging.

- HIV encephalitis and Progressive Multifocal Leukoencephalopathy (PML): The signal in $\mathrm{T} 1$ and $\mathrm{T} 2$, the absence of elevation, the topography, number, bilaterally and symmetry of lesions on MRI, and the regression of viral load after the introduction or modification of triple ARV therapy.

- Lymphoma: The signal in T1 and T2, the topography, number and, annular or nodular enhancement of the lesions on MRI, as well as the absence of improvement under anti-toxoplasma treatment after 10 days and a good response under corticosteroid therapy. 


\subsection{Statistical Analysis}

The data were treated using Epi info 7 software version 2.2.6. The percentages were calculated to describe the qualitative variables. In order to investigate the performance of cerebral tomodensitometry compared to MRI under our practice conditions, the sensitivity, specificity, positive and negative predictive values of the said examination were determined using MRI as reference standard.

\section{Result}

\subsection{Patient Characteristics, Indications and MRI Results}

A total of 39 patients were included during the study period. Their mean age was $37.6 \pm 15$ years with extremes of 18 and 85 years, and their sex ratio was (M/F) 0.6. They all had a plasma Cluster of Differentiation 4 (CD4) lymphocyte count $\leq 200 / \mathrm{mm}^{3}$. The main findings of the MRI are summarised in Table 1. Neurological deficit, convulsions and headaches were the most frequent indications in $34.28 \%, 25.71 \%$ and $17.14 \%$ cases respectively. Among the 39 patients, 35 (89.74\%) had pathological MRI; and toxoplasmosis was the most common diagnosis, $37.14 \%$ (Table 2).

Table 1. Distribution of patients according to magnetic resonance imaging indications.

\begin{tabular}{ccc}
\hline & Frequency $(\mathrm{n})$ & Percentage (\%) \\
\hline Neurological deficit & 12 & 34.28 \\
Convulsions & 9 & 25.71 \\
Headache & 6 & 17.14 \\
Confused state & 4 & 11.43 \\
Prolonged fever & 2 & 5.71 \\
Isolated alteration of general condition & 2 & 5.71 \\
Visual disturbances & 2 & 5.71 \\
Intracranial hypertension & 2 & 5.71 \\
\hline
\end{tabular}

Table 2. Distribution of patients according to the diagnosis made by magnetic resonance imaging.

\begin{tabular}{ccc}
\hline & Frequency (n) & Percentage (\%) \\
\hline Toxoplasmosis & 13 & 37.14 \\
Tuberculosis & 6 & 17.14 \\
Cerebral atrophy & 6 & 17.14 \\
HIV encephalitis & 5 & 14.28 \\
PML $^{\text {a }}$ & 3 & 8.57 \\
Lymphoma & 2 & 5.71 \\
Total & 35 & 100.0
\end{tabular}

aPML: Progressive Multifocal Leukoencephalopathy. 


\subsection{Performance of Cerebral Tomodensitometry Compared with MRI}

Analysis of the results of the 19 patients who had both CT scan and MRI of the brain revealed a sensitivity of $53.33 \%$, a specificity of $100 \%$, a positive predictive value of $100 \%$ and a negative predictive value of $36.36 \%$ for the CT scan of the brain, using MRI as a reference (Table 3). Specifically, MRI was useful in making a diagnosis in 7 patients who had a non-contributory brain CT scan: 3 cases of HIV encephalitis, 3 cases of PML and 1 case of cerebral toxoplasmosis.

\subsection{Elemental Lesions Observed on MRI}

- Cerebral toxoplasmosis: In the 13 patients diagnosed with cerebral toxoplasmosis, the lesions were multiple in $9(69 \%)$ cases and predominantly left-sided in $9(69 \%)$ cases. 28 lesions were found with cortico-subcortical predominance (23 lesions); the supratentorial site was the most frequent (20 lesions); lenticular lesions were also present (3 lesions) (Figure 1) as well as those of the thalamus (2 lesions). The enhancement after gadolinium injection was annular in $9(69 \%)$ cases. Subfalcorial involvement was found in 4 (31\%) patients.

- Tuberculosis: in the 6 patients diagnosed with tuberculosis, there were 2 cases of tuberculoma (Figure 2), 2 cases of cerebral abscess, 1 case of meningoencephalitis and 1 case of meningitis. In the 5 cases of encephalic damage, the lesion was mainly located in the central grey nuclei (3 lesions), followed by the brain stem (1 lesion) and the cerebellum (1 lesion). The lesions were multiple apart from the abscess cases which were rather unique. The latter resulted in diffuse edema with ring enhancement, in contrast to tuberculoma which had a nodular enhancement. In meningitis, a leptomeningeal enhancement after gadolinium injection was found.

- Cortical atrophy: All six patients had an enlargement of the cortical grooves, particularly at the frontotemporal level and dilatation of the lateral ventricles.

- HIV encephalitis: All five patients had diffuse FLAIR and T2 hypersignals of periventricular white matter. The lesions were bilateral and symmetrical, with a T1 isosignal respecting the " $U$ " shaped fibres and the cortical tape. There was no diffusion abnormality, no enhancement after gadolinium injection, and no mass effect (Figure 3). In only one case, cerebellar and peduncular damage were found.

- PML: All three patients had hypersignal T2 and FLAIR patches of periventricular white matter, hyposignal T1, without contrast after gadolinium injection. The lesions were bilateral asymmetrical, only supra-tentorial, with damage to the arched fibres and respect for the cortex. The lesions were single or multiple (Figure 4), and there was no mass effect.

- Lymphoma: In one case it was a single right capsulo-lenticular mass, and in the other multiple sus-tentorial masses with periventricular infiltration. These lesions were hyposignal $\mathrm{T} 1$, isosignal $\mathrm{T} 2$, with intense enhancement after gadolinium injection. Peri-lesional edema and a discrete mass effect (Figure 5) were associated with these lesions. There was no diffusion restriction. 
Table 3. Performance of CT scan compared to MRI for the screening of brain lesions in HIV-infected patients.

\begin{tabular}{cccc}
\hline & Pathological MRIs $^{\mathbf{a}}$ & Normal MRIs & Total \\
\hline Pathological CT $^{\mathrm{b}}$ scans & 8 & 0 & 8 \\
Normal CT scans & 7 & 4 & 11 \\
Total & 15 & 4 & 19 \\
\hline
\end{tabular}

Sensitivity $8 / 15=53.33 \%$; Specificity $4 / 4=100 \%$; Positive Predictive Value: $8 / 8=100 \%$; Negative Predictive Value $=4 / 11=36.36 \%$; ${ }^{\mathrm{a}} \mathrm{MRI}=$ Magnetic Resonance Imaging; ${ }^{\mathrm{b}} \mathrm{CT}=$ Computed Tomography.

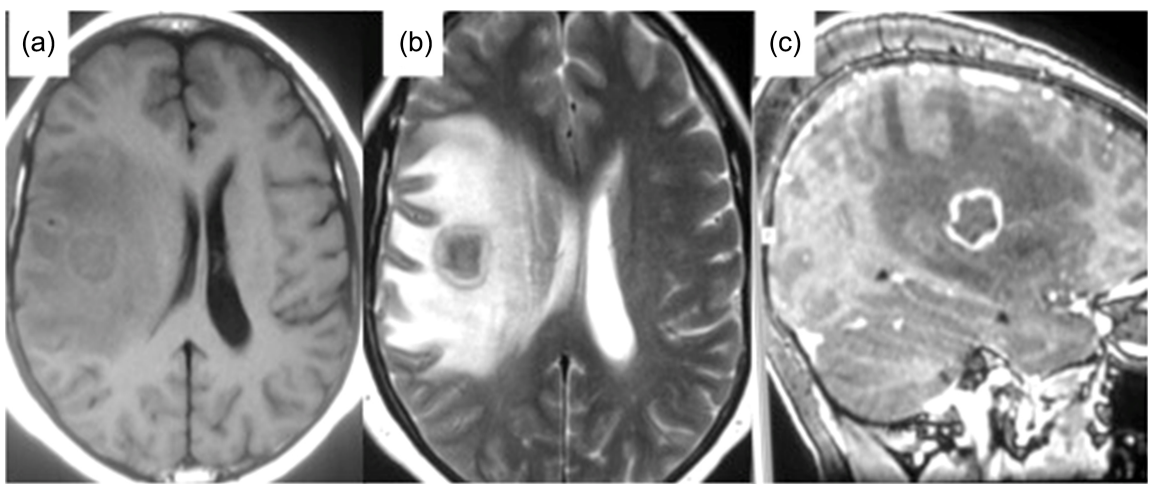

Figure 1. Cerebral toxoplasmosis, isosignal ring image with significant white matter edema in hyposignal T1 (a), hypersignal T2 (b) and a discrete mass effect on the midline. Annular cockade within the edema (c) after gadolinium injection.

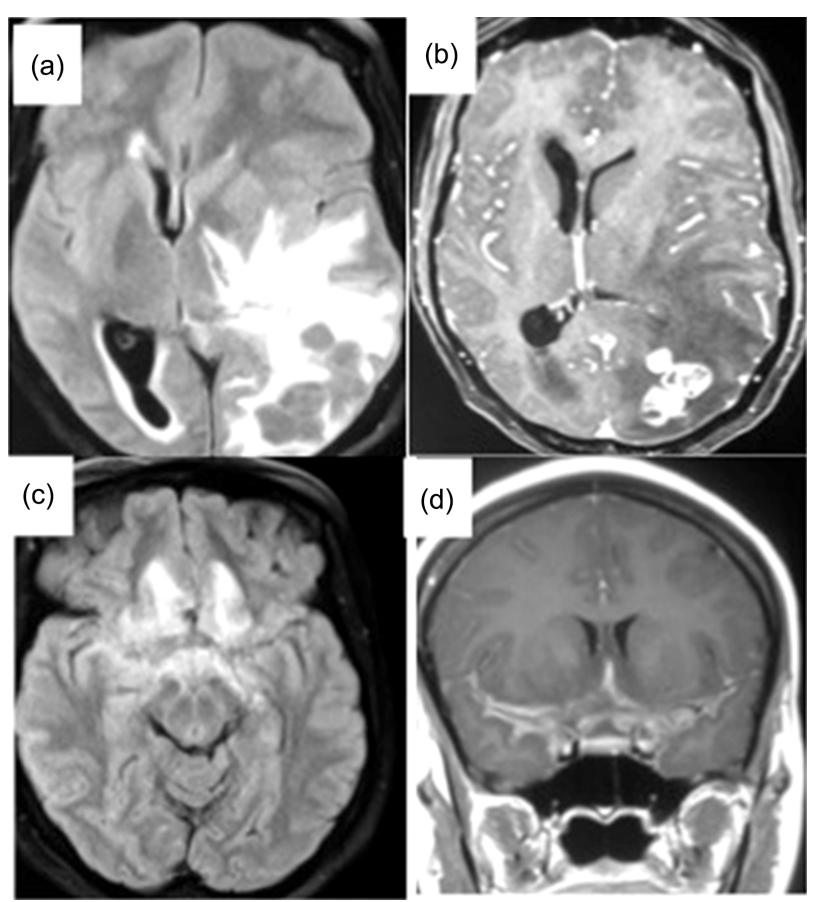

Figure 2. Cerebral tuberculosis. Left temporo-occipital tuberculomas in FLAIR hyposignal (a), associated with hypersignal peri-lesional edema; nodular elevation in "grape clusters" (b) with mass effect on the median structures. Cerebro-meningeal tuberculosis in Hypersignal FLAIR (c) around the cisterns of the base with a meningeal enhancement (d). 


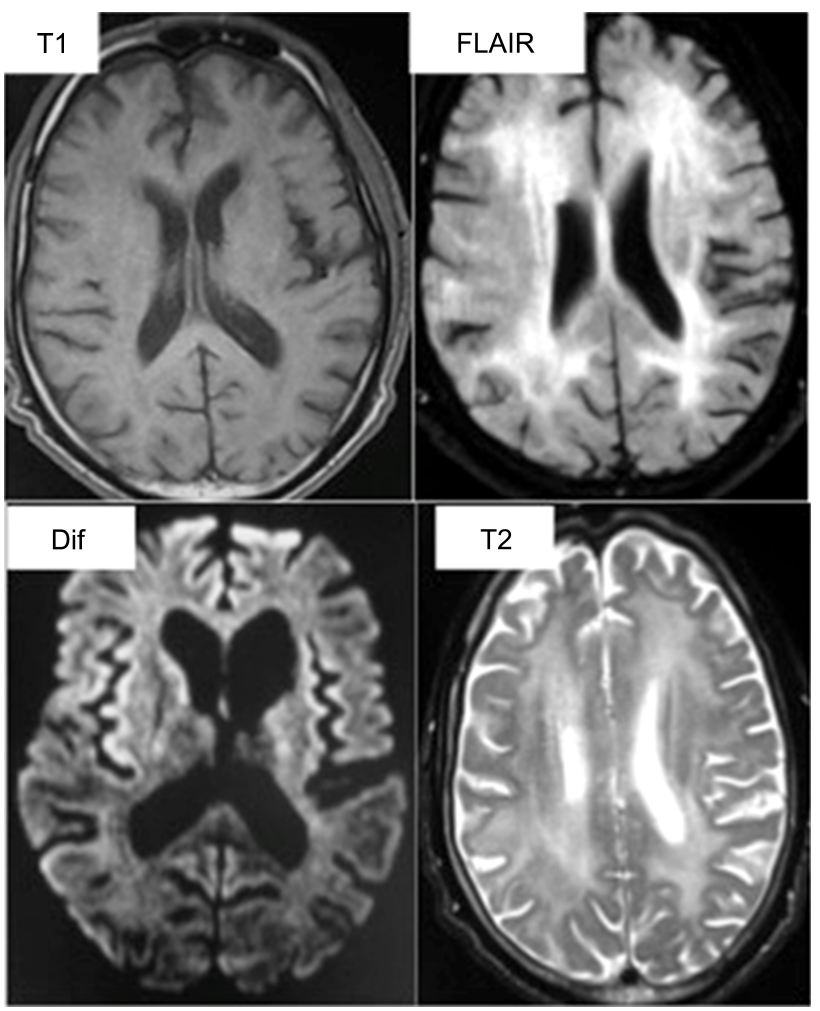

Figure 3. HIV encephalitis. Diffuse range of FLAIR hypersignal and T2 of periventricular white matter, bilaterally symmetrical in T1 isosignal. Absence of mass effect, diffuse abnormality and enhancement after gadolinium injection.

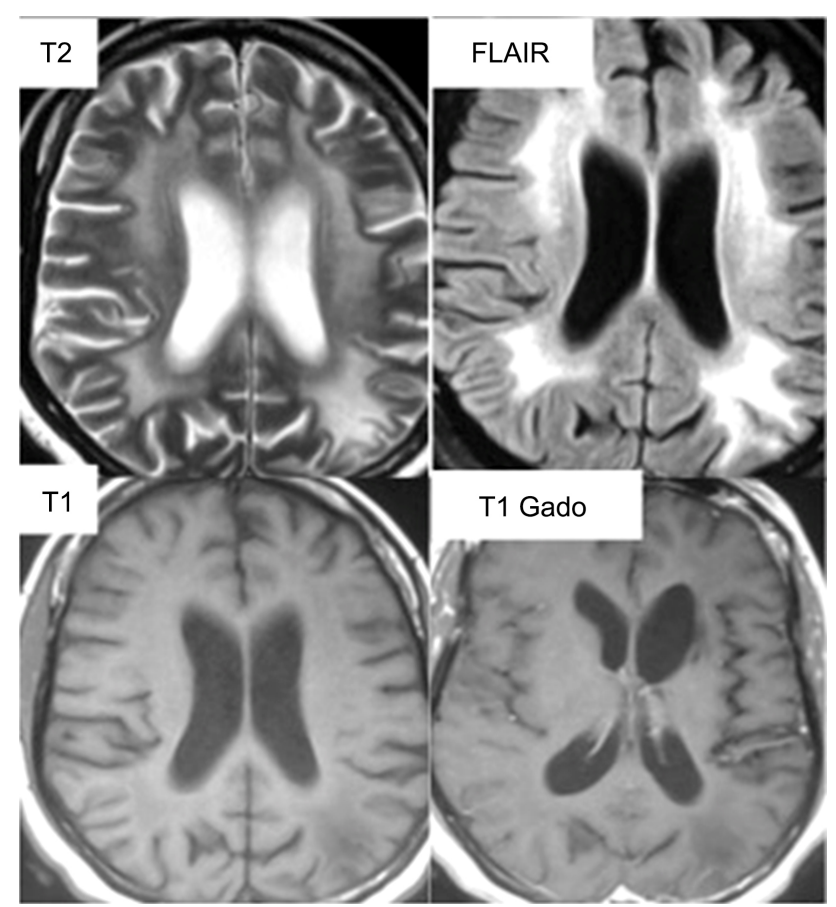

Figure 4. Progressive Multifocal Leukoencephalopathy (PML). Range in hypersignal T2 and FLAIR, in hyposignal T1 of the white substance under the cortex, bilaterally asymmetrical with respect to the cortical ribbon, without enhancement after gadolinium injection. 


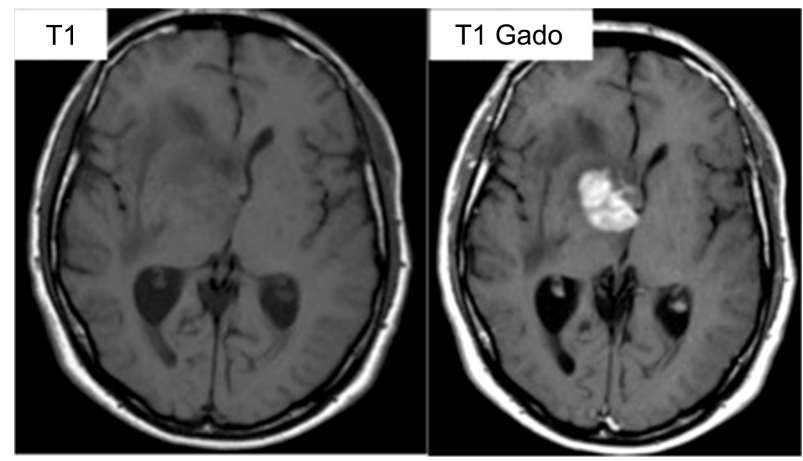

Figure 5. Cerebral lymphoma. Right capsulo-lenticular focal lesion, in T1 hyposignal, with intense enhancement after injection. Note discrete perilional oedema and mass effect.

\section{Discussion}

One of the strengths of this preliminary work is that it is one of the few studies that have taken into account imaging aspects, particularly those of MRI in the diagnosis of brain damage during HIV/AIDS in sub-Saharan Africa; the majority of them are more concerned with epidemiological and clinical aspects for logistical reasons. The main shortcoming is the small sample size. It is justified by the financial and geographical accessibility of MRI, which remains very limited in our cities. Despite this insufficiency, it has led to interesting results, which deserve to be considered.

As found in this work, the predominance of toxoplasmosis has also been reported by other authors in the literature in varying proportions [7] [8] [9] [10]. On the other hand, Costa Gomes et al. in Portugal recorded it as the third cause of CNS abnormality in their series, even if it remained the first cause of opportunistic disease [11]. In almost $70 \%$ of cases, it presented in its typical form, with a ring-shaped elevation and significant peripheral hypodense edema. Its frequent location in the cortico-subcortical region or in the central grey nuclei reported in the literature has also been found [2] [7] [12]. A patient with a normal CT scan had a T1-weighted hyposignal range for ring contrast on MRI. The main differential diagnosis was cerebral lymphoma. The detection of a hypo intense ring in a hyper intense range in T2 weighting and hypersignal in diffusion sequence allowed us to retain the diagnosis of toxoplasmosis. Vinika et al. in California reported a rare case of toxoplasmosis mimicking lymphoma presenting as a T2 and FLAIR hypersignal infiltration of the corpus callosum and central grey nuclei, with an improvement under anti-toxoplasma treatment [13]. Nodular enhancement was less frequent as reported by Pereira-Chioccola et al. [14].

Cerebra-meningeal tuberculosis was the second cause of neurological opportunistic disease diagnosed after toxoplasmosis (17.14\%). The same observation was made by Costa Gomes et al. and by Bhanushali et al., respectively $1.13 \%$ and 20.6\% [10] [11]. The preferred intra-parenchymal locations would be, in order of frequency, the white matter/grey matter junction, the periventricular areas, the posterior cerebral fossa, the central grey nuclei and the mesencephalon [15]. 
In this work, they have all been found, even if a predilection for the junction white substance/grey substance on the above tentorial floor has been noted as in the series of Bhanushali et al. and Moufid et al. [10] [16]. In 125 cases of tuberculomas, $60 \%$ had a supra-tentorial location, eight of which were multiple and two rare, namely the cavernous sinus and the cerebellopontine angle [16]. Intracranial tuberculoma is usually single and multiple forms are rare [17]. Contrary to Moufid et al. who reported a clear preponderance of single tuberculoma (90\%), the cases diagnosed in this work were essentially multiple [16]. Other authors have also reported atypical aspects.

Thus, Koffi et al. described a case of tuberculoma in the form of a plurilobed isosignal lesion poorly limited in T2, heterogeneous with a hypersignal border and a hyposignal background with intense annular contrast after gadolinium injection. The spectrometric analysis was in favour of a glial tumour. The anatomopathological examination allowed the diagnosis to be corrected [18].

In contrast to Costa Gomez et al. who reported $69 \%$ of cases of brain atrophy, making it the leading cause of CNS abnormality in HIV-positive people at work [11], this condition was found in only $17.14 \%$ of the patients investigated in ours, even though they had low CD4 counts. It has been shown that the older untreated infection is, the greater the loss of volume and cortical thinning in several cerebral territories, with regression after initiation of effective antiretroviral treatment [19]. The reasons for the paradoxically low proportion of brain atrophy in this work are not well known and require further investigation. Anomalies in the white matter were also found. For example, HIV encephalitis and PML were represented in $14.28 \%$ and $8.57 \%$ of cases respectively. Elsewhere, they were found in almost similar proportions, ranging from $9.1 \%$ to $17.6 \%$ for encephalitis, and $5.54 \%$ to $14.7 \%$ for PML [10] [11].

In these two diseases, MRI has shown a particular performance, allowing the diagnosis of certain patients for whom a brain CT scan was normal. By offering better spatial and temporal resolution than CT scans, which are less sensitive, MRI can provide discriminatory elements to differentiate PML from HIV encephalitis [20]. Indeed, it shows a diffuse FLAIR and T2 hypersignal of the periventricular, bilateral and symmetrical white matter in T1 isosignal in HIV encephalitis, unlike PML where the lesions are unilateral or asymmetrical bilateral, with the participation of " $U$ " shaped fibres in T1 hyposignal then T2 hypersignal and FLAIR. PML lesions can be single or multiple, without mass effect.

It should be noted, however, that although the diagnosis of PML is quite evocative on MRI, some patients may have diagnostic problems related to an unusual presentation or entanglement of pathologies.

As for the location of the lesions, it was only supra-tentorial. In a work published by Toby et al., a localisation at the level of the brain stem and cerebellum was reported [21].

Finally, with regard to lymphoma, a typical case has been diagnosed, according to the data in the literature, with a capsulo-lenticular localization [22]; but 
also an atypical case with multiple supra-tentorial masses associated with periventricular infiltration. As found above, this condition can be very difficult to distinguish from cerebral toxoplasmosis in its form with nodular enhancement. MRI is of great interest in this case by showing a central hyposignal in $\mathrm{T} 2$, a hypersignal in diffusion (restriction) and a homogeneous enhancement for lymphoma. The low mass effect in relation to tumour volume and the preference for periventricular areas are important arguments for presumption. The test treatment can also be very discriminating, as lymphomas are often very corticosensitive. Ideally, the standard cerebral MRI is supplemented by multimodal sequences, which can provide additional elements in favour of the diagnosis; this could not be achieved in this work. The most evocative sequence is the perfusion, which most often shows an overshoot when the curve returns to the baseline, indicating capillary leakage, whereas hyperperfusion is generally moderate, particularly in relation to malignant gliomas. On spectroscopy, the characteristic aspect is that of a decrease in the $\mathrm{N}$-acetyl-aspartate peak and an increase in choline, often more modest than in malignant glial tumours, associated with a high lipid peak [11] [22].

This work, despite the small number of patients included, demonstrated once again the importance of MRI in the diagnosis of central neurological disorders in HIV-infected subjects and the lower performance of CT scans, particularly for some of them. He pleads for the popularisation of this examination, at least in the major sub-Saharan cities, to improve patient care in this region.

\section{Conclusion}

MRI has played an important role in the diagnosis of central neurological disorders in HIV-infected individuals. It has been particularly useful in recognising cases of HIV encephalitis, PML and even cerebral toxoplasmosis. Improving its accessibility in sub-Saharan Africa should contribute to better care for people living with HIV. Further work based on MRI, and a larger size, will help to better specify the weight and frequency of these neurological conditions in HIV-infected patients at different stages of the disease evolution.

\section{Ethical Considerations}

The publication of the data from this work is in line with the Declaration of Helsinki revised in 2013.

\section{Conflicts of Interest}

The authors declare no conflicts of interest regarding the publication of this paper.

\section{References}

[1] World Health Organization and Gabon. (2016) WHO Cooperation Strategy with Gabon [Stratégie de Cooperation de L’OMS avec le Gabon] 2016-2021. 
https://apps.who.int/iris/bitstream/handle/10665/254892/ccs-gab-2016-2021-fr.pdf? sequence $=1$

[2] Moulignier, A. (2006) Damage to the Central Nervous System and HIV-1 Infection. [Atteintes du Système Nerveux Central et Infection par le VIH-1]. Revue Neurologique, 162, 22-42. https://doi.org/10.1016/S0035-3787(06)74980-3

[3] Oshinaike, O.O., Okubadejo, N.U., Ojini, F.I. and Danesi, M.A. (2010) A Preliminary Study of the Frequency of Focal Neurological Deficits in HIV/AIDS Patients Seropositive for Toxoplasma gondii IgG in Lagos, Nigeria. Nigerian Quarterly Journal of Hospital Medicine, 20, 104-107.

[4] Modi, G., Hari, K., Modi, M. and Mochan, A. (2007) The Frequency and Profile of Neurology in Black South African HIV Infected (Clade C) Patients-A Hospital-Based Prospective Audit. The Journal of the Neurological Sciences, 254, 60-64. https://doi.org/10.1016/j.jns.2007.01.001

[5] De Broucker, T. (2010) Neurologic Manifestations during HIV Infection in Adults [Atteintes Neurologiques par le VIH chez l'Adulte]. La Lettre du Neurologue, 14, 328-337. https://www.edimark.fr/Front/frontpost/getfiles/16826.pdf

[6] Gueddari, F.Z., Bouyacoub, F., Dafiri, R. and Khamlichi, AI. (1998) Magnetic Resonance Imaging of Cerebro-Meningeal Tuberculosis [Imagerie par Résonance Magnétique de la Tuberculose Cérébro-Méningée]. Medecine du Maghreb, 74, 9-15. http://www.santetropicale.com/Resume/7403.pdf

[7] Coulibaly, A., Garba, I., Toure, A., Setcheou, A., Doumbia, M., N’Goan Domoua, A.M. and N'Gbesso, R.D. (2017) Meningo-Encephalic Lesions and State of Immunity during HIV-AIDS in the Tropical Zone [Lésions Méningo-Encéphaliques et Etat d'Immunité au cours du VIH SIDA en Zone Tropicale]. Journal Africain d'Imagerie Médicale, 9, 38-43.

[8] Apetse, K., Niobe, D., Kombate, D., Kumako, V., Guinhouya, K.M., Assogba K., Balogoun, A.A. and Grunitzky E.K. (2015) Opportunistic Infections of HIV/AIDS in a Neurological Unit in Togo [Infections Opportunistes du VIH/SIDA en Milieu Hospitalier Neurologique au Togo]. African Journal of Neurological Sciences, 34. https://ajns.paans.org/infections-opportunistes-du-vih-sida-en-milieu-hospitalier-n eurologique-au-togo

[9] Alkali, N.H., Bwala, S.A., Nyandaiti, Y.W. and Danesi, M.A. (2013) NeuroAIDS in Sub-Saharan Africa: A Clinical Review. Annals of African Medicine, 12, 1-10. https://doi.org/10.4103/1596-3519.108242

[10] Bhanushali, R. and Patil, P.H. (2019) Role of Magnetic Resonance Imaging in Evaluation of the Brain Lesions in HIV-Infected Patients: A Prospective Observational Study. International Journal of Contemporary Medicine, Surgery and Radiology, 4, 34-37.

[11] Gomes, B.C., Nunes, J., Pinto, J., Gouveia, P. and Pais, R.P. (2012) Neuroimaging in Human Imunodeficiency Virus Infection [Neuroimagem na Infecção Vírus da Imunodeficiência Humana]. Acta Médica Portuguesa, 25, 7-12.

https://actamedicaportuguesa.com/revista/index.php/amp/article/viewFile/253/62

[12] Ongolo-Zogo, P., Mbede, M., Kouanfack, C. and Njamnshi, A.K. (2013) Diagnostic and Evolutive Aspects of Toxoplasma Encephalitis in the HIV Positive Patient [Aspects Diagnostiques et Évolutifs de l'Encéphalite Toxoplasmique chez le Patient VIH Positif]. Health Sciences and Disease, 14, 1-4.

https://www.hsd-fmsb.org/index.php/hsd/article/view/197/pdf_18

[13] Chaudhari, V.V., Yim, C.M., Hathout, H., Lai, A. and Donovan, S.M. (2009) Atypical Imaging Appearance of Toxoplasmosis in an HIV Patient as a Butterfly Lesion. 
Journal of Magnetic Resonance Imaging, 30, 873-875.

[14] Pereira-Chioccola, V.L. and Vidal, J.E. and Su, C.L. (2009) Toxoplasma Gondii Infection and Cerebral Toxoplasmosis in HIV-Infected Patients. Future Microbiology, 4, 1363-1379. https://doi.org/10.2217/fmb.09.89

[15] Semlali, S., El Kharras, A., Mahi, M., Hsaini, Y., Benameur, M., Aziz, N., Chaouir, S. and Akjouj, S. (2008) Imaging Features of CNS Tuberculosis [Les Aspects en Imagerie de la Tuberculose du Système Nerveux Central]. Journal de Radiologie, 89, 209-220. https://doi.org/10.1016/S0221-0363(08)70396-2

[16] Moufid, F., Oulali, N., El Fatemi, N., Gana, R., Maaqili, R. and Bellakhdar, F. (2012) The Intracranial Tuberculoma: Report of 125 Cases [Les Tuberculomes Intracraniens: À propos de 125 cas]. The Pan African Medical Journal, 12, 56.

https://www.ncbi.nlm.nih.gov/pmc/articles/PMC3428176/

[17] Artico, M., De Caro, G.M., Carloia, S., Salvati, M., D’Ambrosio, M. and Delfini, R. (1999) Advances in Diagnosis, Treatment and Prognosis of Intracerebral Tuberculomas in the Last 50 Years. Report of 21 Cases. Neurochirurgie, 45, 129-133.

[18] Koffi, P.N., Ouambi, O., El Fatemi, N. and El Maaquili, R. (2019) Cerebral Tuberculoma a Diagnostic Challenge: Case Study and Update. Pan African Medical Journal, 32, Article No. 176. https://doi.org/10.11604/pamj.2019.32.176.16623

[19] Sanford, R., Ances, B.M., Meyerhoff, D.J., Price, R.W., Fuchs, D., Zetterberg, H., Spudich, S. and Collins, D.L. (2018) Longitudinal Trajectories of Brain Volume and Cortical Thickness in Treated and Untreated Primary Human Immunodeficiency Virus Infection. Clinical Infectious Diseases, 67, 1697-1704. https://doi.org/10.1093/cid/ciy362

[20] Feydy, A., Carlier, R., Gray, F., Bernard, L., Mutschler, C., Laure, R., et al. (2000) A Case of Progressive Multifocal Leukoencephalopathy in AIDS: Neuroimaging with Clinical and Pathologic Correlation. Journal de Radiologie, 81, 233-236.

[21] Toby, M., Siddiqui, A. and Kulasegaram, R. (2012) Unmasking of Progressive Multifocal Leukoencephalopathy in a Patient with HIV-2. International Journal of STD \& AIDS, 23, 827-829. https://doi.org/10.1258/ijsa.2012.012057

[22] Houillier, C.-X. (2013) Primary Cerebral Lymphomas [Lymphomes Cérébraux Primitifs]. La Lettre du Neurologue, 17, 124-128.

https://www.edimark.fr/Front/frontpost/getfiles/19611.pdf 